\title{
MEMAKAN HARTA SECARA BATIL (Perspektif Surat An-Nisa: 29 dan At-Taubah: 34)
}

\author{
Taufiq \\ Fakultas Syariah IAIN Lhokseumawe \\ J1. Medan Banda Aceh Km. 275, No. 1 Bukit Rata - Alue Awe, Lhokseumawe \\ e-mail: taufiqmahmud1979@gmail.com
}

\begin{abstract}
The Quran mentions the term treasure in some letters with various derevasion. The mention of the word treasure is accompanied by the procedure of acquisition or utilization. One of them is the probibition of consuming treasure in a vanity way. As many as 36 times a word that means vanity is mentioned in the Quran, including An- Nisa: 29 and At- Taubab: 34. Using a thematic interpretation approach, explores some of the ethical messages contained in these two verses. Forbidden treasures managed by vile. Indications of vanity include the emergence of disillusionment with the parties and be classified as zalim.
\end{abstract}

Kata kunci: consumption, treasure and vanity.

\section{PENDAHULUAN}

P ada dasarnya, syariat Islam 2 mengandung ketentuan-ketentuan tentang amaliah atau perbuatan manusia. Perbuatan manusia secara garis besar ada dua, yaitu perbuatan yang menyangkut hubungan manusia dengan Allah Swt. yang disebut ibadah dan hubungan manusia dengan sesamanya dalam pergaulan hidup bermasyarakat yang disebut muamalah.

Ibadah wajib berpedoman pada sumber ajaran Alqur'an dan al-Sunnah, yaitu harus ada contoh (tata cara dan praktek) dari Nabi Muhammad saw. Konsep ibadah ini berdasarkan kepada mamnu' (dilarang atau haram). Ibadah ini antara lain meliputi Zakat, Puasa, Shalat dan Haji. Sedangkan masalah muamalah (hubungan sesama manusia dan hubungan dengan lingkungan), masalahmasalah dunia, seperti makan dan minum, pendidikan, organisasi, dan ilmu pengetahuan dan teknologi, berdasarkan pada prinsip boleh (jaiz) selama tidak ada larangan yang tegas dari Allah dan RasulNya, termasuk di dalamnya berkenaan dengan harta. Berkaitan dengan hal ini (muamalah), Nabi Muhammad saw mengatakan: "Kalian lebih mengetahui urusan duniamu". (HR. Muslim, no. 2363)

Banyak orang yang mengukur nilai dan martabat seseorang dengan jumlah kekayaannya harta yang dimiliki. Apabila seseorang tersebut kaya maka dianggap mulia, sebaliknya dianggap rendah dan hina. Pada hakekatnya cara yang digunakan dalam memperoleh harta akan berpengaruh terhadap fungsi harta. Orang yang memperoleh harta dengan mencuri, memfungsikannya kebanyakan untuk kesenangan semata, 
seperti mabuk, bermain wanita, judi dan lain-lain. Sebaliknya, orang yang mencari harta dengan cara yang halal, biasanya memfungsikan hartanya untuk hal-hal bermanfaat (Rahmat Syafi'i, 2004: 31).

\section{STUDI LITERATUR}

Harta dalam bahasa Arab disebut "المال" yang berasal dari kata maalayamiilu-mailan yang berarti condong, cenderung, dan miring. Menurut etimologi harta merupakan sesuatu yang di butuhkan dan diperoleh manusia, baik berupa benda yang tampak seperti emas, perak, binatang, tumbuh-tumbuhan maupun (yang tidak tampak), yakni manfaat seperti kendaraan, pakaian, dan tempat tinggal.

Menurut istilah fikih harta mempunyai sinonim makna dengan benda, yaitu segala sesuatu yang mungkin dimiliki seseorang dan dapat diambil manfaatnya dengan jalan biasa (Ahmad Azhar Basyir, 2009: 41).

Kata mal dalam Alquran disebutkan 86 kali pada 79 ayat dalam 38 surah, dan ini tergolong jumlah yang cukup banyak menghiasi sepertiga surah-surah Alquran. Dari 86 kata mal itu terdapat 25 kata berbentuk mufrad dengan berbagai lafal, selanjutnya 61 kali dalam bentuk isim jama' (amwal) dan jumlah ini belum termasuk kata-kata yang semakna dengan mal seperti rizq, mata', qintar dan kanz (perbendaharaan).

Yahya bin Jusoh (Azhari Akmal Tarigan, 2012: 91), mengklasifikasikan makna mal di dalam al-Quran dapat berarti harta yang hina (Q.S. [68]: 10-14, Q.S. [23]: 55-56, Q.S. [26]: 88-89, dan lainlain), harta yang sangat dicintai (Q.S. [89]: 20, dan lain-lain), harta yang menyebabkan manusia berwatak jelek (Q.S. [74]: 12, Q.S. [104]: 2, Q.S. [90]: 6, dll), harta yang dimiliki tidak berguna diakhirat (Q.S. [111]: 2, Q.S. [92]: 11, dan lain-lain), harta yang disesali karena tidak berguna (Q.S. [69]: 28), harta yang berkembang (Q.S. [17]: 6, Q.S. [71]: 12, dan lain-lain), harta sebagai cobaan (Q.S. [2]: 155), harta yang dibangga-banggakan (Q.S. [34]: 35, Q.S. [9]: 69), harta yang membuat manusia menjauhkan diri dari Allah (Q.S. [34] 37), harta yang tidak diperlakukan dengan tidak benar (Q.S. [11]: 87), dan harta yang menyesatkan (Q.S. [10]: 88).

Dari jumlah dan beragam makna harta dalam Alquran, membuktikan betapa besarnya perhatian Islam terhadap harta. Meskipun harta mempunyai sifat yang saling bertolak belakang. Kadangkadang dapat menyelamatkan pemiliknya, namun tak sedikit pula mencelakakan.

Oleh sebab itu, Islam telah mengatur bagaimana caranya seorang muslim dapat memanfaatkan harta yang dimilikinya itu agar berguna bagi kehidupan dunia dan akhirat. Belumlah lengkap jika harta itu hanya dinikmati untuk kepentingan duniawi dan sama sekali tidak berpengaruh pada kehidupan akhirat, keduanya harus mendapat porsi yang 
seimbang. Islam memandang harta sebagai jalan yang mempermudah manusia untuk menuju kesejahteraan (Abdullah Fatah Idris, 1989: 6). bersabda:

Rasulullah shallallahu 'alaihi wasallam

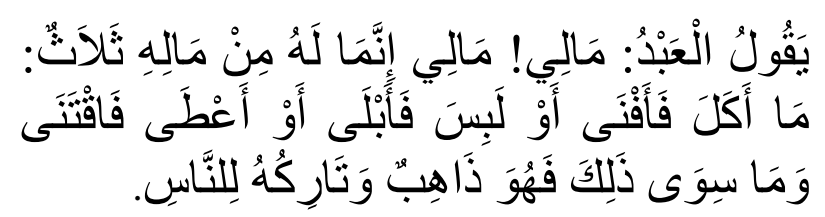

"Seorang hamba berkata: "Hartaku! Hartaku!" Sesungguhnya yang menjadi (harta) miliknya tidak lain hanya tiga: (1) Apa yang dia makan hingga habis, (2) Apa yang dipakai hingga lusuh dan (3) Apa yang dia sedekahkan maka ia disimpan sebagai pahala untuk akhirat. Apa jua selain itu (bukanlah hartanya kerana) dia akan pergi (mati) dan meninggalkannya kepada manusia. (Muslim dalam Shahihnya, hadis No: 2959).

Dalam surat al-Kahfi ayat 46, kata harta disejajarkan dengan anak-anak dan dianggap sebagai perhiasan dunia. Terbukti dalam kehidupan, manusia begitu bangga dengan harta dan keturunan yang dimiliki, sehingga memberikan kehidupan serta martabat yang terhormat bagi yang memilikinya. Alquran pun mencatat beragam kisah yang berkenaan dengan orang-orang yang dicoba dengan harta dan anak.

Harta sangatlah penting dalam menopang kehidupan bahkan menjadi terhormat dengannya, sehingga Alquran menempatkannya demikian juga dengan anak sebagai perhiasan atau sesuatu yang dianggap baik dan indah (zinah) Alquran surah Al-Kahfi: 46 dan Ali Imran: 14. Quraish Shihab menjelaskan, bahwa penamaan keduanya sebagai hiasan (zinah) jauh lebih tepat dari dari pada menamainya qimah (sesuatu yang berharga atau bernilai). Karena kepemilikan harta dan kehadiran anak tidak dapat menjadikan menjadikan seseorang berharga atau mulia. Kemuliaan dan penghargaan hanya diperoleh melalui iman dan amal saleh (M. Quraish Shihab, 2002: 70). Bila merujuk kepada pengertian harta yang didefinisikan oleh kalangan Syafi'iyah, Malikiyah dan Hanabilah, unsur qimah menjadi syarat sesuatu dianggap sebagai harta. dank arena qimah akan dijadikan standar bila terjadi ganti rugi.

\section{METODE PENELITIAN}

Penelitian ini menggunakan metode penelitian kepustakaan (library research). Dengan cara menelaah beberapa tafsir untuk memahami makna surat an-Nisa: 29 dan at-Taubah: 34. Sedangkan al-Quran menjadi sumber utama dalam penelitian ini. Untuk memahami makna memakan harta yang batil dalam al-Quran maka digunakan pendekatan tafsir maudhui' atau tematik. Penggunaan pendekatan metode tersebut karena yang ditelaah dalam penelitian ini hanya fokus pada tema memakan harta secara batil. 


\section{PEMBAHASAN}

\section{Larangan Memakan Harta Secara Batil dalam Al-Quran}

Islam tidak membatasi mencari harta dengan cara apapun, selama tidak melanggar prinsip-prinsip yang telah ditentukan syara'. Karena hukum asal dalam bermu' amalah adalah mubah.

Kaidah menetapkan

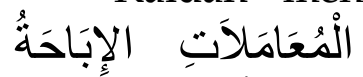
dan

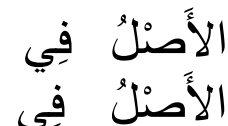

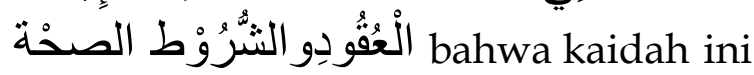
memberikan jalan bagi manusia untuk melakukan berbagai improvisasi dan inovasi melalui sistem, teknik dan mediasi dalam melakukan perdagangan. Namun, Islam mempunyai prinsip-prinsip tentang pengembangan sistem bisnis yaitu harus terbebas dari unsurdharar (bahaya), jahalah (ketidakjelasan) dan zulum (merugikan atau tidak adil terhadap salah satu pihak). Begitu halnya dalam bisnis dengan sistem pemberian bonus harus adil, tidak menzalimi dan tidak hanya menguntungkan orang yang di atas. Dalam artian seluruh rangkaian bisnis juga harus terbebas dari unsur MAGHRIB, singkatan dari lima unsur. 1, Maysir (judi), 2, Aniaya (zulum), 3. Gharar (penipuan), 4 Haram,5, Riba (bunga), 6. Iktinaz atau Ihtikar dan 7. Bathil.

Begitu bernilainya harta bagi kehidupan manusia, Alquran juga memberikan memberikan batasanbatasan umum dalam bermuamalah, salah satunya larangan memakan harta secara batil. Dan ini menjadi bukti bahwa Islam memiliki konsep etika bagaimana melindungi hak dan kekayaan orang lain agar tidak dilanggar dan dirampas. Termasuk kegiatan konsumsi harus menghindari prilaku zalim dan batil (Abdul Karim Al-Khatib, 1976: 151-152).

Kata batil (Ahmad Warson Munawwir, 1997: 92) memiliki kata dasar bathil yang bermakna fasad atau rusak, sia-sia, tidak berguna, bohong. Al baathil sendiri berarti sesuatu yang batil, yang salah, yang palsu, yang tidak berharga, yang sia-sia dan syaitan.

Ar-Raghib al-Asfahani (Abi alQasim al-Husain bin Muhammad arRaghib Al-Asfahani, 1961: 50-51) menjelaskan, al baathil bermakna lawan dari kebenaran yaitu segala sesuatu yang tidak mengandung apaapa didalamnya ketika diteliti atau diperiksa atau sesuatu yang tidak ada manfaatnya baik di dunia maupun diakhirat. Shihab menyebutkan bahwa makna bathil yaitu segala perkara yang diharamkan Allah SWT atau tidak ada haknya. Dalam artian pelanggaran terhadap ketentuan agama atau persyaratan yang disepakati. Dalam konteks ini dikaitkan dengan sabda Nabi SAW: "kaum muslimin sesuai dengan (harus menepati) syarat-syarat yang mereka sepakati, selama tidak menghalalkan yang haram atau mengharamkan yang halal".

Kata al-bathil dalam Alquran terdapat 36 kali dengan berbagai derivasinya. Bathala disebut satu kali dalam surah al- 'Araf ayat 11, tubthilu dua kali dalam surah al-Baqarah ayat 264 dan surah Muhammad ayat 33. Yubthilu satu kali dalam surah al-Anfal ayat 8 dan sayubthiluhu satu kali dalam 
surah Yunus ayat 81. Dibanding bentuk kata lainnya, kata bathilun disebut paling banyak yaitu 24 kali dalam AlQuran. Bathilan disebut dua kali dan mubthilun disebut lima kali (Muhammad Fuad Abdul Baqi, 1981: 123-124).

Wahbah Az-Zuhaili dalam kitabnya Tafsir al Wajiz wa Mu'jam Ma'aniy al Qur'an al 'Aziz, menjelaskan bahwa kata bathil dalam Alquran yang berhubungan dengan memakan harta manusia secara batil ada di 4 tempat, yaitu: Al-Baqarah ayat 188, an-Nisa ayat 29 dan 161, dan at-Taubah ayat 34 . Dalam makalah ini akan dibahas 2 ayat dari 4 ayat yang berhubungan dengan memakan harta manusia dengan batil, yaitu an-Nisa ayat 29 dan at-Taubah ayat 34 .

\section{a. Surat an-Nisa ayat 29.}

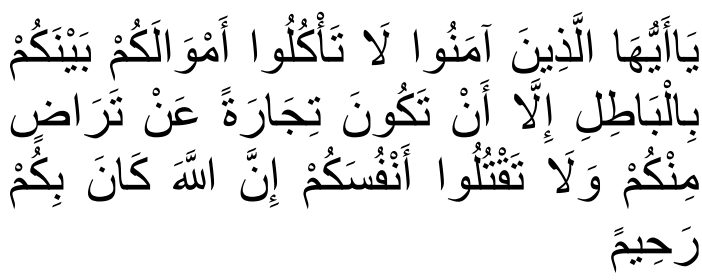

"Hai orang-orang yang beriman, Jangan kamu memakan harta-harta saudaramu dengan cara yang batil, kecuali harta itu diperoleh dengan jalan dagang yang ada saling kerelaan dari antara kamu. Dan jangan kamu membunuh diri-diri kamu, karena sesungguhnya Allah Maha Pengasih kepadamu".

Berkenaan dengan asbabun nuzulnya, Sayyid Qutub (Sayyid Qutb, 2004: 239) menyebutkan tidak bisa dipastikan secara tegas kapan ayat tersebut diturunkan. Apakah sesudah atau sebelum pengharaman riba. Jika turun sebelum pengharaman riba maka ayat ini berfungsi sebagai peringatan awal tentang pelarangan riba, jika turun setelah pengharaman riba, maka ayat ini berfungsi sebagai penjelasan terhadap sebagai salah satu larangan mengambil harta manusia secara batil.

Surat an-Nisa ayat 29 tersebut merupakan larangan tegas mengenai memakan harta orang lain atau hartanya sendiri dengan jalan bathil. Memakan harta sendiri dengan jalan batil adalah membelanjakan hartanya pada jalan maksiat. Memakan harta orang lain dengan cara batil ada berbagai caranya, seperti pendapat Suddi, memakannya dengan jalan riba, judi, menipu, menganiaya. Termasuk juga dalam jalan yang batal ini segala jual beli yang dilarang syara' (Syekh. H. Abdul Halim Hasan Binjai, 2006: 258).

Wahbah Az-Zuhaili (AzZuhaili Wahbah, 1997: 84) menafsirkan ayat tersebut dengan kalimat janganlah kalian ambil harta orang lain dengan cara haram dalam jual beli, (jangan pula) dengan riba, judi, merampas dan penipuan. Akan tetapi dibolehkan bagi kalian untuk mengambil harta milik selainmu dengan cara dagang yang lahir dari keridhaan dan keikhlasan hati antara dua pihak dan dalam koridor syari'. Tijarah adalah usaha memperoleh untung lewat jual beli. Taradhi (saling rela) adalah kesepakatan 
yang sama-sama muncul antar kedua pihak pelaku transaksi, jual beli tanpa ada unsur penipuan.

Al Maraghi (Mustafa AlMaraghi, 2004) menjelaskan makna kata al-bathil dalam ayat tersebut berasal dari kata-kata al-bathlu dan buthlan yang bermakna sia-sia dan kerugian. Sedangkan menurut syara' adalah mengambil harta tanpa imbalan yang benar dan layak serta tidak ada keridhaan dari pihak yang diambil. Atau menghabiskan harta dengan cara yang tidak benar dan tidak bermanfaat. Termasuk katagori al-bathil: mengundi nasib, al-ghasy, $k h i d a^{\prime}$, riba dan ghabn. Begitu juga menghabiskan harta pada tempat yang haram, dan menghabiskannya pada tempat yang tidak bisa diterima oleh logika sehat.

Menurut al-Biqa'iy (Burhan alDin Abi al-Hasan Ibraim ibn Umar Al-Biqa'iy, 2006: 368) al-batil berarti segala sesuatu yang dari berbagai seginya tidak diperkenankan Allah, baik aspek esensinya atau sifatnya. Sedangkan al-Razi (Fakhr al-Din Muhammad ibn Umar ibn al-Husayn al-Tamimiy Al-Razi, 1990: 57) membaginya ke dalam dua makna, pertama, sesungguhnya segala sesuatu yang tidak dihalalkan oleh hukum syara', kedua, mengambil sesuatu milik orang lain tanpa pengganti.

Baidhawi (Abdullah bin Umar bin Muhammad al-Asy Syirazi Baidhawi, n.d: 276) memberikan penafsiran mengenai surat an-Nisa ayat 29, yaitu mendapatkan harta yang tidak diperbolehkan syariat seperti ghasab, riba dan lotre.
Al-Lusi (Syihabuddin Sayyid Mahmud Al-Lusi, n.d: 302) menafsirkan harta batil tersebut yang didapatkan dengan unsur menzalimi, yaitu dengan riba dan lotre. Al-Tabari (At-Thabari, 2001: 83) menjelaskan bahwa makna memakan harta dengan batil dalam surat an-Nisa tersebut yaitu janganlah diantara kalian memakan harta orang lain dengan jalan yang diharamkan, seperti riba, lotre dan sebagainya dari harta yang diharamkan Allah dari padanya. Sedangkan Ibnu Abdul As-Salam (Izuddin Ibnu Abdul As-Salam, 1996: 96) menafsirkannya dengan cara lotre, riba, ghasab, dengan zalim atau akad yang rusak.

Dari beberapa definisi bathil yang dijelaskan oleh para mufassirin di atas baik oleh Wahbah Az Zuhaili, al Maghri dan lain-lainnya terhadap penafsiran ayat an-Nisa 29, tidak menunjukkan perbedaan signifikan, contoh definisi yang diberikan oleh Wahbah Az Zuhaili lebih pada menunjukkan cara memperoleh harta, sedangkan definisi yang diberikan al Maghari fokus pada cara menggunakan. Yang kesemuanya menyebutkan bahwa prilaku memakan harta secara batil ialah prilaku yang mendatangkan kezaliman bagi orang lain. Di antaranya dalam bentuk riba, lotre (maisir), ghasab (mencuri), khianat dan sebagainya.

Dikaji dari munasabah dengan ayat sebelumnya (an-Nisa ayat 28) tidak ada kaitannya. Namun, Ibnu 'Asyur berpandanga bahwa terdapat pada ayat-ayat sebelumnya yang 
berkenaan dengan hukum-hukum waris, nikah dan mengandung beberapa perintah untuk menunaikan menunaikan harta kepada yang berhak.

\section{b. Surah At-Taubah ayat 34}

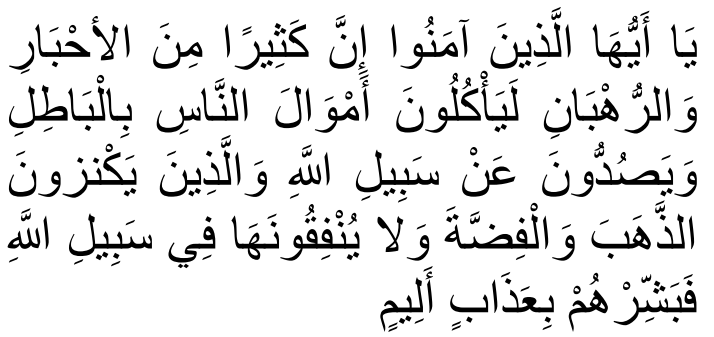

"Hai orang-orang yang beriman, sesungguhnya sebagian besar dari orang-orang alim Yahudi dan rahibrahib Nasrani benar-benar memakan harta orang dengan jalan yang batil, dan mereka menghalang-halangi (manusia) dari jalan Allah. Dan orang-orang yang menyimpan emas dan perak dan tidak menafkahkannya pada jalan Allah, maka beritahukanlah kepada mereka (bahwa mereka akan mendapat) siksa yang pedih"

Penulis tidak menemukan secara rinci asbabun nuzul ayat 34 surat at-Taubah ini, namun ada sebuah hadist yang berkenaan dengan persoalan penimbunan emas dan perak yang sebagian mufassir mengkaitkan dengan ayat ini. Yaitu hadis yang bersumber dari Zaid bin Wahb, berkenaan dengan orangorang yang menimbun emas. Zaid berkata, "Saya melewati Rabdzah, dan ternyata bertemu dengan $\mathrm{Abu}$ Dzar radhiyallahu 'anhu, aku pun berkata kepadanya, "Apa yang menjadikan kamu menempati tempat ini?" Ia menjawab, "Aku berada di Syam, lalu aku berselisih dengan $\mathrm{Mu}^{\prime}$ awiyah tentang ayat, "Dan orang-orang yang menyimpan emas dan perak serta tidak menginfakkannya di jalan Allah..." Mu'awiyah berkata, "Ayat ini turun berkenaan Ahli Kitab", sedangkan aku berkata, "Ayat ini turun berkenaan dengan kita dan mereka." Itulah masalah yang terjadi antara aku dengannya." Ia pun menuliskan surat kepada Utsman radhiyallahu 'anhu mengeluhkan tentang aku, maka Utsman mengirim surat kepadaku yang isinya, "Datanglah ke Madinah", maka aku pun datang, lalu banyak orang yang mengerumuniku seakan-akan mereka belum pernah melihatku sebelumnya, kemudian aku terangkan hal itu kepada Utsman, lalu ia berkata kepadaku, "Jika engkau mau, engkau menjauh, namun engkau dekat." Itulah yang menjadikan aku menempati tempat ini, dan jika sekiranya mereka memerintahkan aku sebagai penduduk Habasyah, maka aku akan mendengar dan taat." Hadist ini diriwayatkan oleh Imam Bukhari.

Para mufassir di antaranya Ibnu Katsir (Ibnu Katsir, 2004: 420) menjelaskan bahwa maksud al-bathil dalam ayat ini adalah prilaku mayoritas tokoh agama Yahudi dan Nasrani menjual agama untuk memperoleh dunia, dengan menggunakan posisi dan jabatan agama mereka sebagai justifikasi 
untuk memperoleh harta masyarakat (umatnya) menurut nafsu mereka, seperti mengwajibkan hadiah dan pajak.

Selanjutnya Ibnu Katsir menjelaskan bahwa mereka yang disebutkan dalam ayat tersebut merupakan pemimpin manusia golongan ketiga, karena sesungguhnya manusia merupakan beban bagi para ulama, semua hamba Allah, dan orang-orang yang memiliki harta. Apabila keadaan mereka rusak, maka keadaan manusia pun rusak pula, seperti apa yang dikatakan oleh Ibnu Mubarrak dalam bait syairnya:

"Tiada yang merusak agama kecuali para raja, orang-orang alim dan para rahib (su')".

Yusuf al-Qardhawi (Yusuf AlQardhawi, 2014: 80) menjelaskan bahwa yang dimaksudkan dengan "memakan" dalam ayat tersebut adalah menerima, mengambil dan menguasai. hal ini diungkapkan dengan "memakan" sebagai kiasan.

Ayat ini memberikan pesan kepada orang-orang yang beriman agar tidak berprilaku sebagaimana orang-orang alim Yahudi dan rahibrahib Nasrani, yang mengambil dan menggunakan harta orang lain dengan jalan batil, antara lain dengan menerima sogok, memanipulasi ajaran untuk memperoleh keuntungan materi. Mereka menampakkan diri sebagai agamawan yang dekat dengan Tuhan dan seolah-olah mementingkan akhirat tetapi hakekat mereka tidak demikian.
Perilaku memakan harta orang dengan jalan batil yang mereka lakukan dengan cara mengambil harta itu dengan cara menyuap untuk mengubah aneka hukum dan syariat, dan meyakinkan orang lain bahwa dirinya merupakan orangorang yang pandai dan terampil dalam menafsirkan ayat serta menjelaskan kandungan ayat-ayat Allah. "memakan" diungkapkan dengan "mengambil". Padahal yang dicela hanyalah mengambil harta secar batil, karena memakan merupakan tujuan utama dari mengambil.

$$
\text { Asy-Sya'rawi (Asy-Sya'rawi, }
$$
1999: 754) mengemukakan bahwa salah satu aspek kemukjizatan alQuran adalah uraian ayat ini di mana Allah swt. menguraikan tentang emas dan perak, dua jenis barang tambang yang dijadikan Allah sebagi dasar penetapan nilai uang dan alat tukar dalam perdagangan, kendati ada barang tambang lainnya yang lebih mahal dan berharga. Tetapi, demikianlah keadaannya hingga kini diseluruh dunia kedua barang tambang itu masih tetap menjadi dasar bagi perdagangan dan nilai uang setiap negara.

Keterkaitan ayat 34 surat atTaubah (munasabah) dengan sebelumnya, maka ayat 34 surat atTaubah ini tidak memiliki munasabah dengan sebelumnya. Pada ayat 33 atTaubah sebelumnya berkenaan dengan prilaku orang-orang Yahudi dan Nasrani yang menjadikan pendeta dan rahibnya sebagai Tuhan mereka. Dan tidak mempercayai 


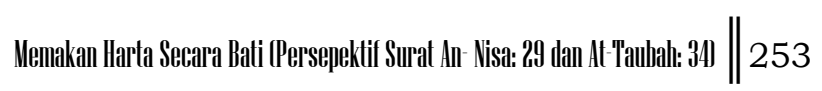

para rasul sebagai utusan Allah. Sedangkan ayat 34 tersebut bisa dipahami bahwa harta yang termasuk dalam golongan batil tidak hanya harta yang sudah jelas diketahui bahwa jalan yang ditempuh dengan sesuatu cara yang zalim, namun harta yang didapatkan secara halal saja dapat berubah status menjadi batil, apabila tidak dimanfaatkan sesuai dengan ketentuan syara' seperti menahan tidak diproduktifkan.

\section{Pesan Etika Ekonomi dalam An-Nisa: 29 dan at-Taubah: 34}

Memahami makna ayat (An-Nisa ayat 29 dan at-Taubah ayat 34) bahwa katagori prilaku batil adalah yang membuat orang lain tidak ridha karena hak-hak kebendaannya terzalimi. Dalam surat an-Nisa 29 dengan jelas Allah mengaitkan perkara perbuatan batil dengan sikap ridha dalam perdagangan (tijarah). Begitu juga dengan at-Taubah ayat 34, prilaku para pendeta Nasrani dan rahib Yahudi yang berprilaku batil dengan membebankan para pengikutnya pajak dan hadiah atas nama agama. Begitu juga dengan prilaku penimbunan, adanya keengganan untuk melakukan investasi dengan cara-cara yang dibenarkan. Dan bila dikaitkan dengan persoalan ekonomi modern kedua konten ayat ini adalah bahagian dari etika bisnis.

Beberapa referensi menyebutkan ada perbedaan makna dalam bahasa arab mengenai perbuatan menimbun. Jika yang ditimbun itu adalah makanan maka digunakan dengan kata ihtikar, selain itu diistilahkan dengan kanzun.
Kedua bentuk prilaku tersebut digolongkan kepada prilaku batil dan mendatangkan kezaliman kepada orang lain. Karena seharusnya harta tersebut dapat diproduktifkan dan mendatangkan kemaslahatan justru ditahan tanpa keperluan yang diperbolehkan oleh syara'. Sebagaimana kaidah fiqiyah menyebutkan:

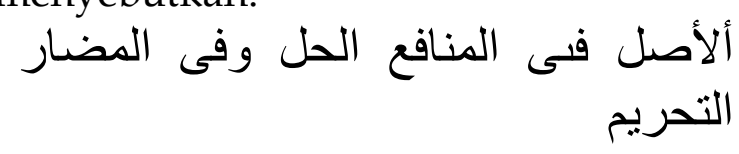

"Pada dasarnya semua yang bermanfaat boleh dilakukan dan semua yang mendatangkan bahaya haram dilakukan".

Sikap keridhaan para pihak merupakan salah satu asas pokok dalam muamalah yang disebut dengan mabda' ar-radhaiyyah. Oleh karena itu transaksi barulah sah apabila didasari oleh kerihaan kedua belah pihak (A Djazuli, 2006: 130). Sebuah kaidah fiqhiyah menyebutkan:

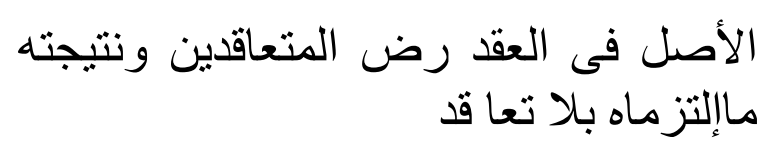

"Hukum asal dari transaksi adalah keridhaan kedua belah pihak yang berakad, hasilnya adalah berlaku sahnya yang diakadkan".

Rasulullah saw. Bersabda:

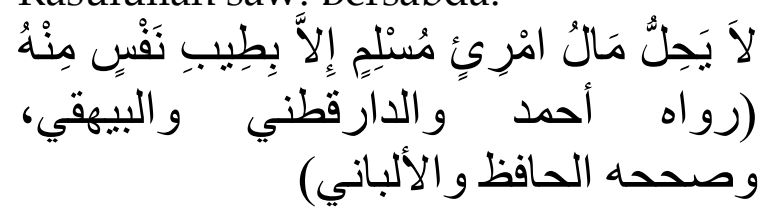

"Tidaklah halal harta seorang muslim kecuali dengan dasar kerelaan darinya". 
(Riwayat Ahmad, Ad Daraquthny, Al Baihaqy dan dinyatakan sebagai hadits shahih oleh Al Hafizh Ibnu Hajar dan Al Albany).

Selain masalah keridhaan juga berkaitan dengan prilaku zalim terhadap orang lain, ketika hak-hak mereka dikhianati dan ditahan, tentu akan mendatangkan kezaliman. Prinsip ekonomi Islam juga sangat melarang prilaku tersebut, sesuai dengan kaidah: Prinsip latazlimuna wala tuzlamun merupakan juga bahagian dari prinsipprinsip yang dilarang dalam perdagangan. Prinsip ini selain mendatangkan kerugian bagi yang lain juga bagi sendiri pelaku. Kalimat latazlimuna wala tuzlamun dapat ditemukan pada surah al-Baqarah ayat 279:

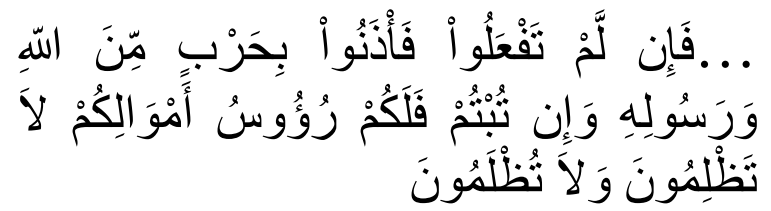

“... Jika kamu tidak mengerjakan (meninggalkan sisa riba), maka ketahuilah, bahwa Allah dan Rasul-Nya akan memerangimu. Jika kamu bertobat (dari pengambilan riba), maka bagimu pokok hartamu. Kamu tidak menganiaya dan tidak (pula) dianiaya." (Q.S. AlBaqarah [2]: 279).

Ayat tersebut berhubungan dengan orang-orang makan riba sebagaimana ayat sebelumnya. Dalam kitab Fathul Bayan Fi Maqashid al-Qur'an (Shadiq Hasan Khan, n.d:) dijelaskan bahwa kata latazlimuna bermakna jangan mendhalimi orang yang sudah penuh hutang dengan mengambil tambahan (riba nasi'ah). Sedangkan makna wala tuzlamun bahwa penjual tidak boleh terdhalimi oleh pembeli dengan menunda pembayaran bagi pembeli yang mampu atau mengurangi harga barang.

Ibnu Khaldun (Ibnu Khaldun, 2006: 741) mengatakan" Ketahuilah bahwasanya kedhaliman terhadap harta manusia akan menghilangkan harapan mereka dalam mencari dan memperolehnya. Karena mereka memandang bahwa akhir dan ujung dari usaha mereka akan hilang dari tangan mereka. Jika harapan mereka dalam mencari dan memperoleh harta telah hilang, maka mereka akan berhenti dari bekerja. Bila kedhaliman tersebut telah banyak dan menyentuh semua pintu mata pencaharian, maka akan terjadi mogok kerja diseluruh lini usaha, karena harapan untuk memperoleh harta telah hilang (dari masyarakat) secara keseluruhan.

Dalam sebuah hadits qudsi Allah berfirman yang berkenaan dengan keharaman berbuat zalim:

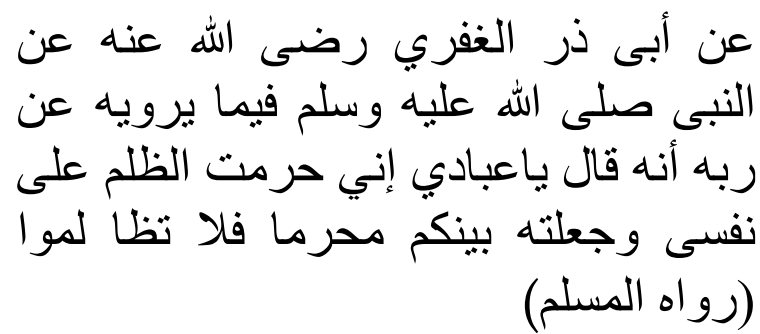

“Dari Abi Dzar al-Ghifari r.a. dari Nabi saw. menyampaikan apa yang diterimanya dari Rabbnya, bersabda, "Wahai hamba-hamba-Ku, sesungguhnya Aku telah mengharamkan kezaliman atas diri-Ku dan Aku menjadikannya haram di antara kalian, maka janganlah kalian saling menzalimi." (Muslim, n.d: 123) 


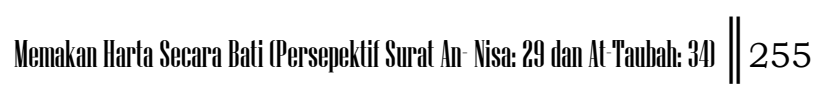

Dalam hadits itu Allah SWT menegaskan bahwa Allah mengharamkan diriNya berbuat zalim, mustahil diriNya berbuat zalim kepada makhlukNya. Padahal Allah Maha Kuasa melakukan apapun yang dikehendaki. Semestinya manusia sebagai hamba Allah juga tidak mengerjakan sesuatu yang mendatangkan kedhaliman bagi orang lain dan juga dirinya.

Jadi jelaslah, kezaliman terlarang dalam semua keadaan, dan keadilan adalah wajib dalam semua keadaan, sehingga dilarang berbuat zalim kepada orang lain, tidak mesti hanya sesama muslim tapi juga dengan non muslim.

Syekhul Islam Ibnu Taimiyah menyatakan, "Semua kebaikan masuk dalam keadilan dan semua kejelekan masuk dalam kezaliman. Oleh karena itu, keadilan adalah perkara wajib dalam setiap sesuatu dan atas setiap orang, dan kezaliman dilarang pada setiap sesuatu dan atas setiap orang, sehingga dilarang menzalimi seorang pun-baik muslim, kafir, atau zalim-, bahkan boleh atau wajib berbuat adil terhadap kezaliman juga." Beliau pun menyatakan, "Semua yang Allah larang kembali kepada kezaliman dan semua yang diperintahkan kembali kepada keadilan".

Allah swt. berfirman:

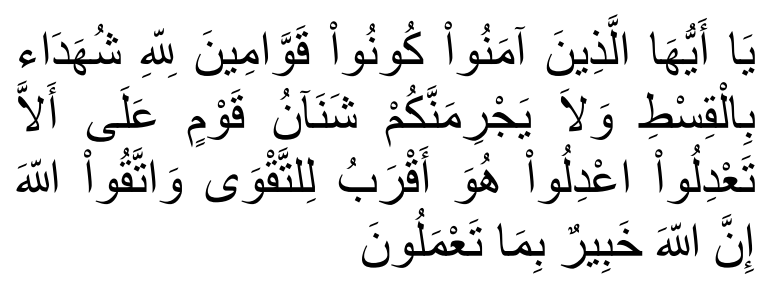

"Wahai orang-orang yang beriman, hendaklah kamu jadi orang-orang yang selalu menegakkan (kebenaran) karena Allah, menjadi saksi dengan adil. Janganlah sekali-kali kebencianmu terhadap sesuatu kaum, mendorong kamu untuk berlaku tidak adil. Berlaku adillah, karena adil itu lebih dekat kepada takwa. Dan bertakwalah kepada Allah, sesungguhnya Allah Maha: Mengetahui segala sesuatu yang kamu kerjakan." (Q.S. Al-Maidah [5]: 8).

Kezaliman merupakan sumber kerusakan dan keadilan adalah menjadi sumber bagi terwujudnya kemaslahatan dalam setiap aktivitas manusia, dan juga pangkal bagi kesuksesan di dunia dan akhirat. Ketika perniagaan atau muamalah adalah pintu yang besar bagi kezaliman manusia dan pintu untuk memakan harta orang lain dengan batil, maka larangan zalim dan pengharamannya termasuk maqashid syariah terpenting dalam bermuamalah. Kewajiban berbuat adil dan larangan berbuat zalim menjadi kaidah terpenting dalam muamalah.

Banyak bentuk-bentuk kezaliman yang jika dilihat dalam realitas kehidupan, namun secara garis besar, kezaliman dapat dibagi pada dua kategori, yakni:

1. Pertama: نفس (kezaliman terhadap diri sendiri). Puncak kezaliman terhadap diri sendiri adalah al-isyraku billah (menyekutukan Allah). Karena orang yang menyekutukan Allah telah menempatkan makhluk pada posisi Al-Khaliq seraya memuja, menyembah, dan mengabdi 
kepadanya. Dan itulah perilaku menempatkan sesuatu bukan pada tempatnya yang paling buruk dan paling dahsyat. Dan kebanyakan julukan zhalimin (orang-orang yang zalim) dalam Al Quran ditujukan kepada orang-orang musyrik.

2. Kedua: ظلم عبد لغيره (kezaliman seorang hamba terhadap orang lain). Kezaliman banyak macamnya, jika dikaitkan dengan adil maka kezaliman disini adalah jika seseorang tidak berbuat adil baik itu terhadap dirinya, orang tua, kerabat ataupun kaum tertentu.

Prinsip latazlimuna wala tuzlamun juga sejalan dengan kaidah fiqhiyah yaitu:

$$
\begin{aligned}
& \text { لاضرر ولاضرار } \\
& \text { "Tidak mudharat dan tidak } \\
& \text { memudharatkan. }
\end{aligned}
$$

Begitu juga disebutkan dalam kaidah mu'amalah bahwa:

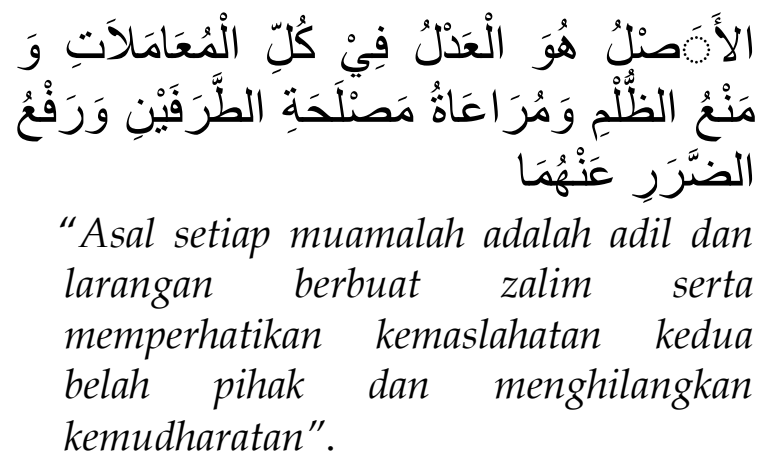

Pada asalnya, dalam seluruh akad transaksi harus adil, dan demikianlah yang diajarkan syariat Islam. Dan sudah menjadi kesepakatan semua syariat Allah untuk mewajibkan keadilan dan mengharamkan kezaliman. Allah mengutus para Rasul-
Nya dengan membawa kitab-kitab suci dan neraca keadilan, agar manusia menegakkan keadilan pada hak-hak Allah dan makhluk-Nya, sebagaimana firman Allah swt. Dalam surah alHadid ayat 25:

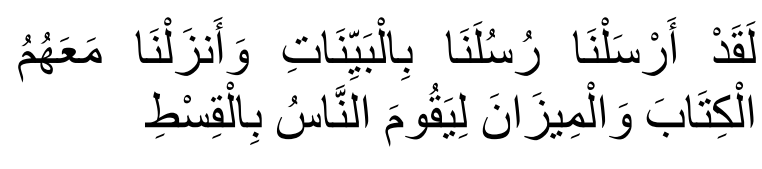

"Sesungguhnya Kami telah mengutus rasul-rasul Kami dengan membawa bukti-bukti yang nyata, serta telah Kami turunkan bersama mereka al-Kitab dan neraca (keadilan) supaya manusia dapat melaksanakan keadilan." (Q.S. AlHadid [57]: 25).

Di antara pelanggaran atau unsur dari prinsip latazlimuna wala tuzlamun adalah atazlimuna wala tuzlamun sebagaimana disebutkan oleh Adiwarman (Adiwarman A Karim, 2010: 33) adalah gharar, riba dan ihtikar. Ketiga unsur tersebut sangat memungkinkan terjadi dalam praktek perdagangan atau bermuamalah. Dan ketiganya bukan hanya mendatangkan kerugian bagi pembeli namun juga bagi pedagang sendiri. Baik itu dari segi kualitas, kuantitas, harga maupun waktu.

\section{PENUTUP}

Ada dua makna mengenai memakan harta secara batil yang disebutkan dalam Surat an-Nisa ayat 29 dan at-Taubah ayat 34. Pada surat an-Nisa ayat 29 menyebutkan larangan memakan yang menurut mufassir bahwa makna larangan memakan adalah setiap usaha baik cara 


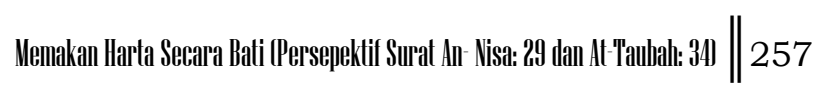

memperoleh maupun memanfaatkan harta.

Sedangkan surat at-Taubah ayat 34 menegaskan larangan melakukan penimbunan harta berupa emas dan perak. Ayat ini berkenaan dengan perilaku pendeta dan rahib yang suka memakan harta umatnya secara batil.

Meskipun terletak pada surat yang berbeda, kedua ayat tersebut (an-Nisa: 29 dan at-Taubah: 34) mnegaskan tujuan yang sama yaitu larangan memakan baik cara memperoleh maupun memanfaatkan. Surat an-Nisa ayat 29 menegaskan tentang urgensi keridhaan dalam memakan harta yang sifatnya barang konsumtif, maka pada surat at-Taubah ayat 34 menegaskan tentang larangan memanfaatkan harta dengan jalan menimbun (kanz) yaitu pada barang-barang bersifat produktif (emas dan perak). Karena kedua perilaku batil tersebut dapat memicu kesenjangan (gap) pasar secara global.

\section{DAFTAR KEPUSTAKAAN}

Al-Asfahani, Abi al-Qasim al-Husain bin Muhammad ar-Raghib. 1961. Mufradat fiGharib al- qur 'an,. Mesir: Maktabah wa Matba'ah Musthafa.

Al-Biqa'iy, Burhan al-Din Abi al-Hasan Ibraim ibn Umar. 2006. Nazhm alDurar fi Tanasub al-Ayat wa al-Suwar. Beirut: Dar al-Kutb al-Ilmiyyah, Jilid I.

Al-Khatib, Abdul Karim. 1976. As-Siyasah al-Maliyah fi al-Islam ea Shilatuhu bi al$M u^{\prime}$ amalah al-Mu'ashirah. Kairo: Dar al-Fikr al-'Arabi.

Al-Lusi, Syihabuddin Sayyid Mahmud. n.d. Ruh al-Ma'aani fi Tafsir al-Quran Adhim wa as-Sabil Matsani. Beirut: Dar Ihya at-Turats al-A'rabi.

Al-Maraghi, Mustafa. 2004. Tafsir AlMaraghi. Beirut: Dar al-Kutub al'Ilmiyah.

Al-Qarhawi, Yusuf. 2014. 7 Kaidah Utama Fikih Muamalah, Terj. Fedrian Hasmand. Jakarta: Pustaka AlKautsar.

Al-Razi, Fakhr al-Din Muhammad ibn Umar ibn al-Husayn al-Tamimiy. 1990. Mafatih al-Gaib. Beirut: Dar alKutb al-'Ilmiyyah, Jilid V.

As-Salam, Izuddin Ibnu Abdul. 1996. Tafsir al-Quran: Ikhtisar an-Nukat lil Mawardi. Beirut: Dar Ibnu Hazmen.

Asy-Sya'rawi. 1999. Tafsir Asy-Sya'rawi (Jilid. VII). al-Qahirah: Akhbar alYaum.

At-Thabari. 2001. Jami al-Bayan an Ta'wil al-Quran. Kairo: Dar Hijr, Cet. I.

Baidhawi, Abdullah bin Umar bin Muhammad al-Asy Syirazi. n.d. Anwar al-Tanzil wa as-Rarut Ta'wil. Beirut: Dar Ihya Turatd al-Arabi.

Baqi, Muhammad Fuad Abdul. 1981. Mu'jam Mufahrasy li Alfadz Al-Quran. t.p.t.

Basyir, Ahmad Azhar. 2009. Asas- Asas Hukum Muamalat (Hukum Perdata Islam). Yogyakarta: UII Press.

Binjai, Syekh. H. Abdul Halim Hasan. 2006. Tafsir Al-Ahkam. Jakarta: Kencana, cet. 1.

Djazuli, A. 2006. Kaidah-kaidah Fikih: Kaidah-kaidah Hukum Islam dalam Menyelesaikan Masalah-masalah yang 
Praktis. Jakarta: Pranata Media.

Ibnu Katsir. 2004. Tafsir, al-Quran al-Azim Jilid II. Mesir: Dar al-Kutub alIlmiyah.

Ibnu Khaldun. 2006. Muqaddimah. Mesir: Dar Nahdhah Mishr, Juz. II.

Idris, Abdullah Fatah. 1989. Kedudukan Harta Menurut Pandangan Islam. Jakarta: Kalam Mulia.

Karim, Adiwarman A. 2010. Bank Islam Analisis Fiqih dan Keuangan.. Jakarta: Rawali Pers, cet. VII.

Khan, Shadiq Hasan. n.d. Fathul Bayan fi Maqashid al-Qur'an.: Darul Fikri al'Arabi, Juz. I.

Munawwir, Ahmad Warson. 1997. alMunawwir. Surabaya: Pustaka Progressif.
Muslim. n.d. Shahih Muslim bi Syarhi AnNawawi. Kairo: Dar Dakwah alIslamiyah, Juz. XVI.

Qutb, Sayyid. 2004. Tafsir fidhilalil quran. Beirut: Dar Asy-Syuruk, Juz II.

Shihab, M. Quraish. 2002. Tafsir Al-Misbah: Pesan, Kesan, dan Keserasian Al-Quran. Jakarta: Lentera Hati.

Syafi'i, Rahmat. 2004. Fiqh Muamalah. Bandung: Pustaka Setia.

Tarigan, Azhari Akmal. 2012. Tafsir Ayatayat Ekonomi: Sebuah Eksplorasi Melalui Kata-kata dalam Al-Quran. Bandung: Cita Pustaka Media Perintis.

Wahbah, Az-Zuhaili. 1997. Tafsir al Wajiz wa Mu'jam Ma'aniy al Qur'an al 'Aziz. Damsyik: Dal al Fikr. 